\title{
Experimental force measurements in single point incremental sheet forming SPIF
}

\author{
Badreddine Saidi $^{1,4, a}$, Atef Boulila ${ }^{2},{\text { Mahfoudh } \text { Ayadi }^{3} \text { And Rachid Nasri }}^{4}$ \\ 1 Institut Supérieur des Études Technologiques de Radès, ISETR, BP 176, 2098 Radès Médina, Tunisie \\ 2 Institut National des Sciences Appliquées et de Technologie INSAT, BP 676, 1080 Tunis Cedex, Tunisie \\ 3 École Nationale d'ingénieurs de Bizerte ENIB, Manzel Abderrahmen, Tunisie \\ ${ }^{4}$ Laboratoire de Mécanique Appliquée et Ingénierie LR-MAI, ENIT, BP 37, 1002 Tunis, Tunisie
}

Received 11 June 2014, Accepted 8 February 2015

\begin{abstract}
This paper provides the experimental protocol, of the process of a single point incremental sheet forming "SPIF", allowing predicting the efforts of forming. To speak about parameters of a single point incremental sheet forming (SPIF), we should find the good parameter for judgement. A prediction of the forming force during the SPIF process is selected to ensure the safe use of the tooling and machinery, in particular when using a robot or a milling machine not designed for the process. During the incremental forming process, considerable forces can occur depending on the studied material, the thickness of the sheet, the tool steps. In this work, the influence of several parameters on the evolution of the axial forming force during the incremental forming of a truncated cone is studied. A set of experiments is carried out using steel and aluminium sheets. The results on the most influent process parameters can be used to optimize the process. The results obtained are compared with those found by finite element simulations.
\end{abstract}

Key words: Incremental sheet forming / efforts of forming / numerical simulation

\section{Introduction}

Asymmetric incremental sheet forming (AISF) is a process of materials forming, which implies several parameters, such as, the working conditions, the trajectory of the tool and the behaviour of studied material. The single point incremental sheet forming (SPIF) is a recent, innovative process, with the blank positioned on a matrix and fixed with a blank holder, and the hemispherical punch brought into rotation controlled by a CNC milling machine.

The beginning of the incremental sheet forming process is granted by the work carried out by Leszak [1], according to which the sheet is deformed locally by a small punch, patented under the name of "forming without mould". Since the process was almost forsaken, following the developments of the CNC machine ordered, the evolution of CAD, made possible to the developers to plan the trajectories of the punch for using the process.

With this intention it is imperative to pass by the knowledge of the factors affecting this process such as the working conditions, the shape and the trajectory of the punch and the behaviour of studied material [1].

\footnotetext{
${ }^{a}$ Corresponding author: badreddinesaidi@yahoo.fr
}

With the aim of giving work domain to these factors and of optimizing them, during the time of an operation of incremental forming, it is necessary to find a criterion of judgement. More than one criterion is defined and the researchers are in front of a variety of traditional criterion.

The force of forming seems to be the most significant parameter to judge the behaviour of the punch and blank [2]. During the incremental forming process, considerable forces can occur depending on the studied material, the thickness of the sheet, the tool diameter. A control of these process parameters is necessary in order to improve the final product quality. Moreover a good knowledge of the forming forces is important in order to ensure the safe use of the tooling and machinery used during the process, especially when using a robot or a CNC machine not designed for the process. In this work during the SPIF process, the axial force is the dominating force component.

The investigations on the matter are due to Jeswiet et al. [3], Flice et al. [4], Dufflou et al. [5,6]. Several works were done with the aim of setting up the limiting diagram of forming for incremental forming at a point SPIF and were carried out with Flice et al. [4], Jeswiet et al. [3] and Park [7]. The surface quality in all the processes is related to several parameters. The results of work of Jeswiet 


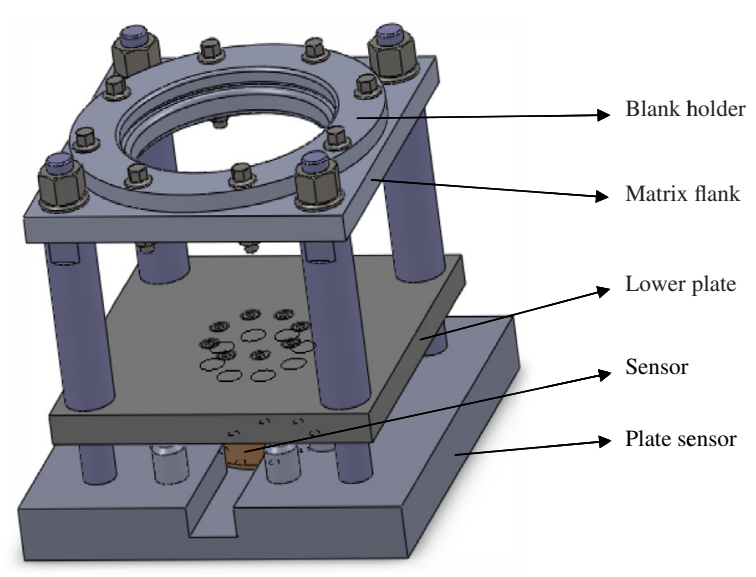

Fig. 1. Experimental device of a single point incremental sheet forming SPIF.

et al. [3], Durante et al. [8], confirm that the increment $(\Delta z)$ decreases the roughness, but the angle of part and the diameter of punch increase this feature. However other results can be retained, like the estimation of the friction coefficient.

This paper investigates the effect of various parameters on the axial forming force generated during the forming process of a truncated cone. It is a preliminary study that tends to provide a basis for the construction of an optimization model of the process.

\section{Materials and methods}

\subsection{Materials}

Experimental device of a single point incremental forming SPIF is carried out with a 3 -axis CNC vertical milling machine. The device is fixed onto a 3 axis sensor of forces (3 forces in CNC axis) to carry out tests thereafter enabling us to follow the behaviour of the efforts of forming all by varying the factors affecting the process. The experimental device of a single point incremental sheet forming SPIF is presented by its overall drawing in Figure 1, consisted mainly of two blocks. A lower sole is attached on the table and only bound by means of the sensor of force with the block containing the blank to be deformed. Simple clamps allow maintaining the blank in position during the movement of the tooling system.

Monitoring and measurement of the forces are provided by a multi-component sensor FN7325-M6 shown in Figure 2, which measures the effort up $15000 \mathrm{~N}$, and couples up 200 N.m, in three directions $X, Y, Z$, with an operating range of $-20^{\circ}$ to $80^{\circ}$, with sensibility drift in compensated range lower than $5 \times 10^{-4}{ }^{\circ} \mathrm{C}^{-1}$.

The wide range of electronic packaging and processing for the sensor power supply and signal amplification, provides a complete measuring chain matched, calibrated and ready for use.

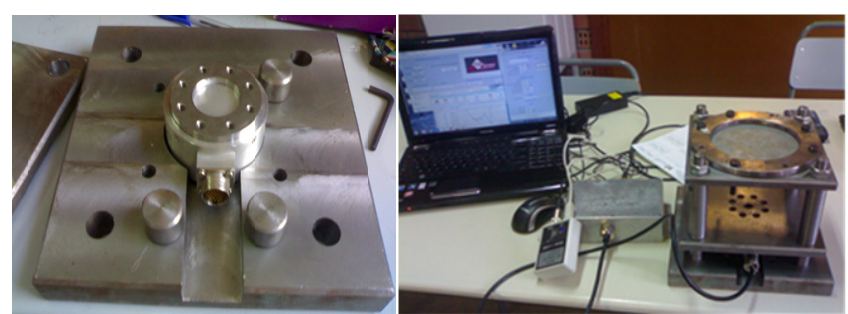

Fig. 2. The multi-components sensor FN7325.

Table 1. Materials mechanical characteristics.

\begin{tabular}{ccccc}
\hline Material & $E[\mathrm{MPa}]$ & $R p 0.2[\mathrm{MPa}]$ & $R m[\mathrm{MPa}]$ & $A \%$ \\
\hline AA1050-O & 70000 & 300 & 535 & 40 \\
$304 \mathrm{~L}$ & 210000 & 350 & 620 & 50 \\
\hline
\end{tabular}

\subsection{Experimental methods}

The forming punch consists in a bronze element with $20 \mathrm{~mm}$ diameter and hemispherical end shape, the values of the diameters already used are varying between $8 \mathrm{~mm}$ and $30 \mathrm{~mm}[4,8]$.

The materials used for the corresponding investigations are aluminium (AA 1050) and steel (304 L), whose mechanical characteristics appear in Table 1.

The tests are carried out, varying the thickness $(e)$ of blank, the angle of inclination $(\alpha)$ of the part to be realized, and the increment of descent of the punch $(\Delta z)$, with an aim of seeing their effects on the behaviour of the efforts of forming.

The blanks are prepared and cut with dimensions of the device by Laser cutting.

The part is realized with the form of a truncated cone of variable diameter and angle of external inclination of $90 \mathrm{~mm}$ and a depth being able to reach $40 \mathrm{~mm}$.

The test device is mounted on a vertical milling machine CNC NUM REALMECA type C2 1040F 3-axis and a power of $3.7 \mathrm{~kW}$ and a maximum spindle speed of $(4000 \mathrm{rpm})$ given by Figure 3 . The tests are carried out with a rotational frequency $N=700 \mathrm{rpm}$, an axial speed in advance $V_{\mathrm{Fa}}=400 \mathrm{~mm} \cdot \mathrm{mn}^{-1}$ and a radial speed in advance $V_{\mathrm{Fr}}=400 \mathrm{~mm} . \mathrm{mn}^{-1}$. The punch immersed in an oil bath posed on blank, crosses a circle with a diameter $90 \mathrm{~mm}$, and then it carries out a jump of $(\Delta z)$ to the bottom and remakes the same trajectory, by creating a spiral giving the shape of the part (Fig. 4).

\section{Experimental results and discussion}

\subsection{Effects of the material}

Aspect of the evolution of the efforts in single point incremental sheet forming (SPIF) represented by the axial component $(F z)$ in the Figure 5, explains that to deform an aluminium sheet one has needed a force not exceeding $(250 \mathrm{~N})$. On the other hand this force must be multiplied almost by four $(1000 \mathrm{~N})$ to deform the same stainless steel sheet. 


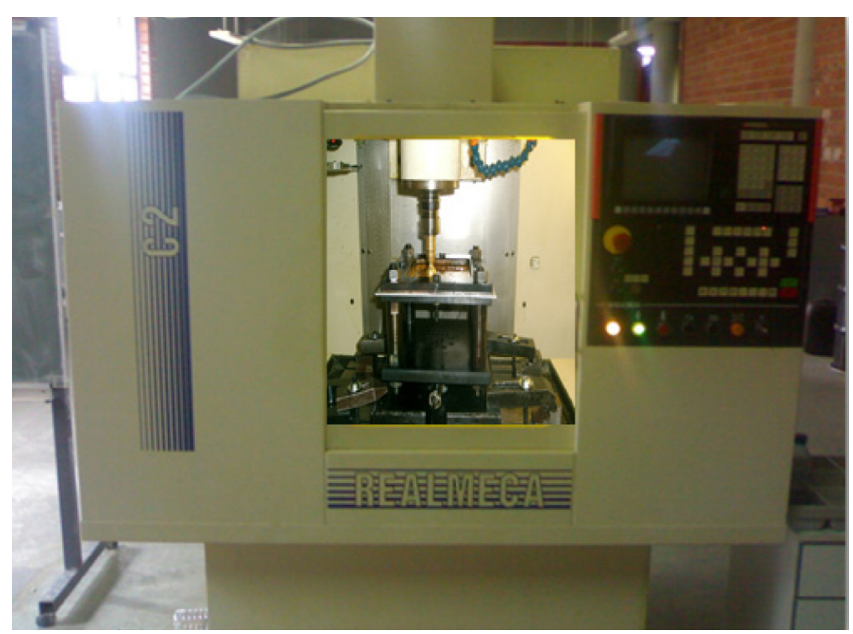

Fig. 3. Experimental device with a 3 -axis $\mathrm{CNC}$ vertical milling machine.
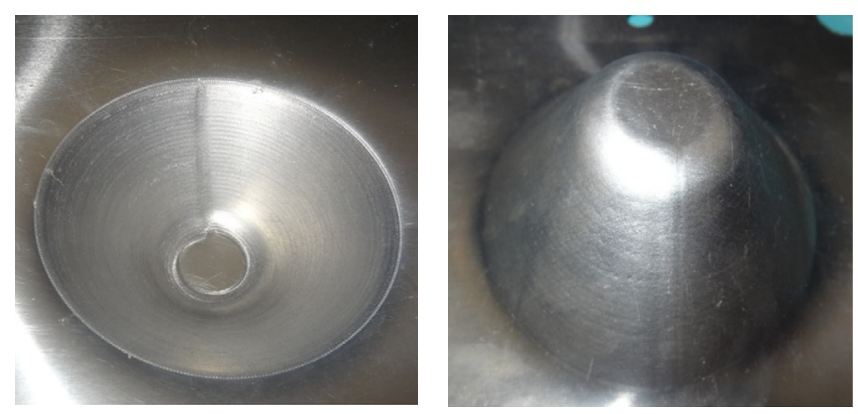

Fig. 4. Parts realized with experimental device of SPIF.

In the case of sheet of aluminium alloy, all along forming while passing from one increment to another the $F z$ force reaches a maximum after almost five $(10 \mathrm{~mm})$ increments to establish itself with this value until the end of forming. This result is explained by the compensation of the efforts by the effect of hardening work, provided by Ambrogio [9], On the other hand in the case of the forming of steel sheet the establishment of the effort is obtained only on the level of the forming of the 12 th $(24 \mathrm{~mm})$ increment, that is explained by a rate of significant hardening work at this stage because of the significant thinning of sheet during the phase of the lengthening most solicited which passes by this stage of deformation $[2,4]$.

Each time the material has a significant mechanical resistance to the rupture strength, and requires more effort for its plastification, and nevertheless it remains to locate the margins of these efforts which are themselves functions of several factors in progress of studies.

\subsection{Effects of the thickness (e)}

We present the evolution of the axial forming force versus depth corresponding to a vertical tool step $(\Delta z)$ of (2 mm), a wall angle of $\left(30^{\circ}\right)$ and $\left(45^{\circ}\right)$ by using different values of the thickness $(0.5 \mathrm{~mm}, 0.8 \mathrm{~mm}, 2 \mathrm{~mm})$ in the case of the steel sheet.

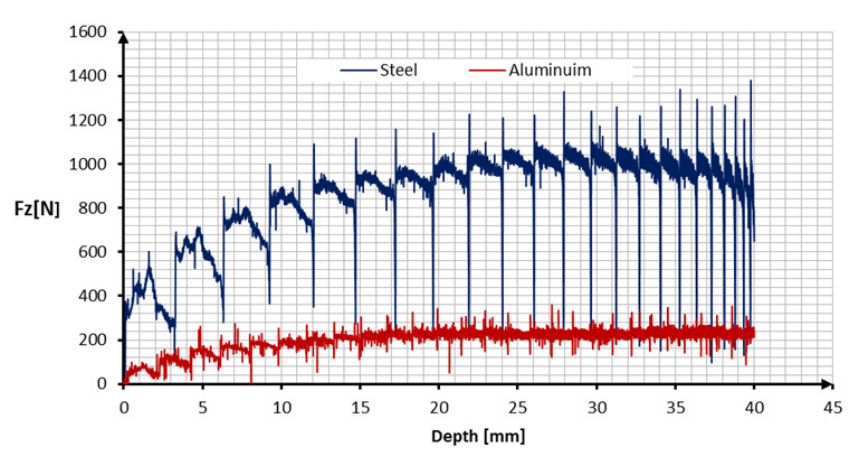

Fig. 5. $F z$ curve in SPIF with variation of material $(e=$ $2 \mathrm{~mm}, \Delta z=2 \mathrm{~mm}$ and $\alpha=30^{\circ}$ ).

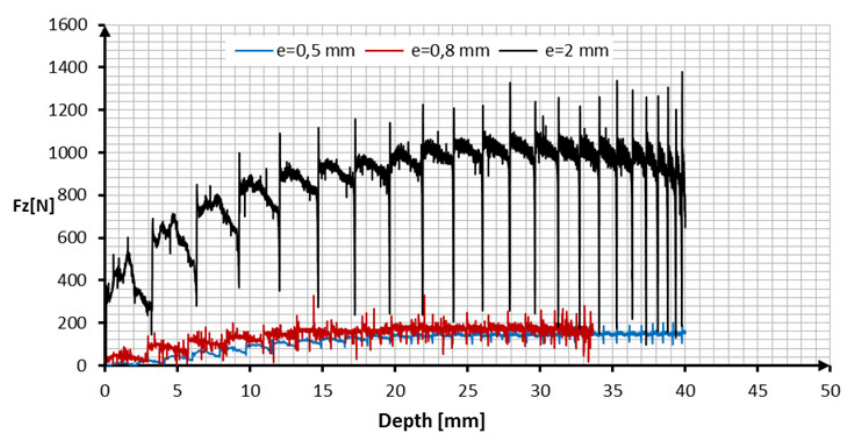

Fig. 6. $F z$ curve in SPIF with variation of thickness (e) (steel $304 \mathrm{~L}, \Delta z=2 \mathrm{~mm}, \alpha=30^{\circ}$ ).

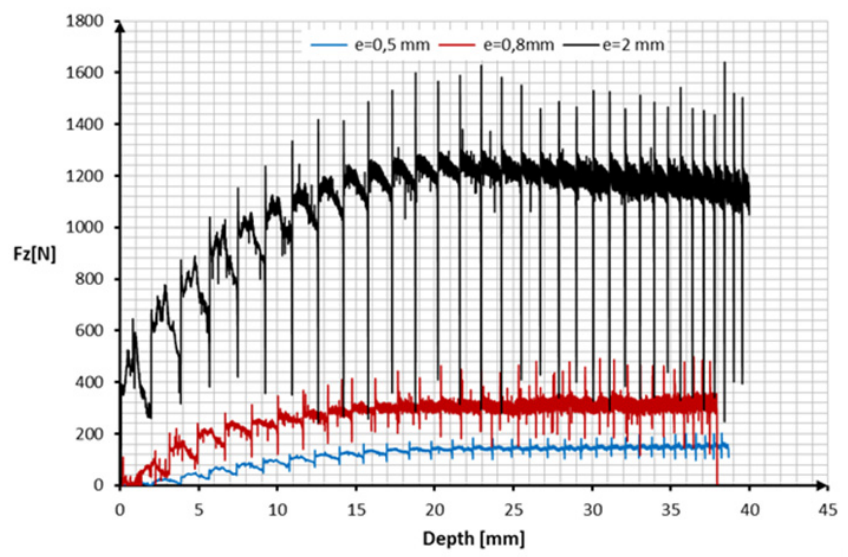

Fig. 7. $F z$ curve in SPIF with variation of thickness (e) (steel $304 \mathrm{~L}, \Delta z=2 \mathrm{~mm}$ and $\alpha=45^{\circ}$ ).

We present here the effect of the sheet thickness on the variation of the axial force $F z$. Figures 6 and 7 , illustrate these variations in the case of steel $(304 \mathrm{~L})$ for two angles $\left(\alpha=30^{\circ}\right.$ and $\left.\alpha=45^{\circ}\right)$ with various thicknesses.

When the thickness increases the force becomes increasingly significant. For a $(0.8 \mathrm{~mm})$ thickness this force is $(300 \mathrm{~N})$, if this thickness reaches $2 \mathrm{~mm}$ the force takes a value of approximately $(1200 \mathrm{~N})$. This result confirms those of the work already published by Filice [4], Ambrogio [9] on the level of the forces. 


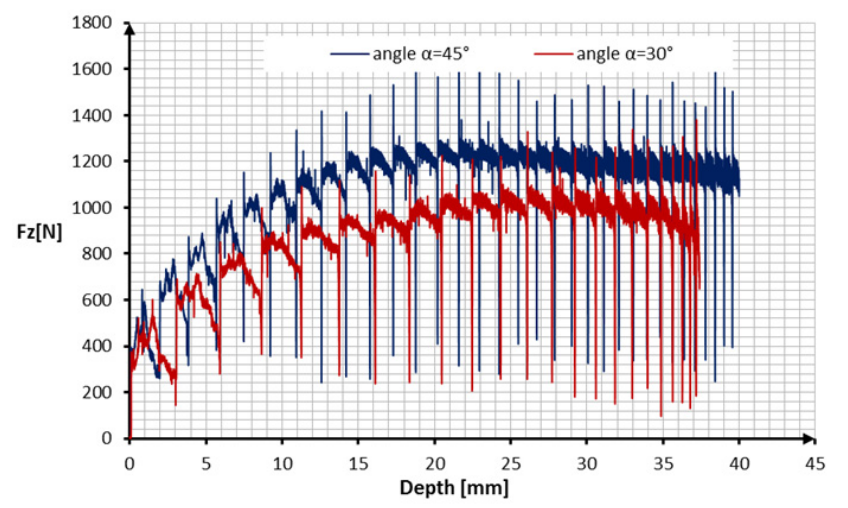

Fig. 8. $F z$ curve in SPIF with variation of angle $(\alpha)$ (steel $304 \mathrm{~L}, \Delta z=2 \mathrm{~mm}$ and $e=2 \mathrm{~mm}$ ).

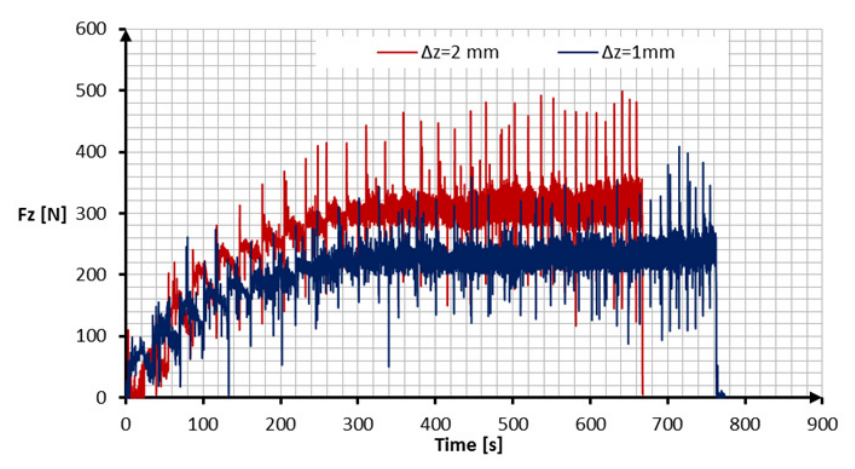

Fig. 9. $F z$ curve in SPIF with variation of increment $(\Delta z)$ (steel $304 \mathrm{~L}, \alpha=30^{\circ}$, and $e=2 \mathrm{~mm}$ ).

\subsection{Effects of the inclination angle $(\alpha)$}

Figure 8 shows that the increase of the wall angle provides an increase of the axial forming force results confirmed by published works by Filice [4], Ambrogio [9]. A reduction of the forming force after the force peak can be observed for the curve obtained with a wall angle of $45^{\circ}$. It can be explained by the thinning of the sheet.

\subsection{Effects of the descent increment $(\Delta z)$}

In our case of study we choose to use the model of the increment to move from a contour to another during forming. This step is characterized by a jump on the same line of the steps towards the interior $(\Delta x=\Delta y)$ and to the bottom $(\Delta z)$ creating the form with the help of sought dimensions.

The component $F z$ of force increases by keeping its form when the increment $(\Delta z)$ increases. Figure 9 presents the $F z$ force in SPIF with a angle $\alpha=30^{\circ}$ of steel material part. For the same quality of material, the results are confirmed by Filice [4], Ambrogio [9] on the level of paces and values.

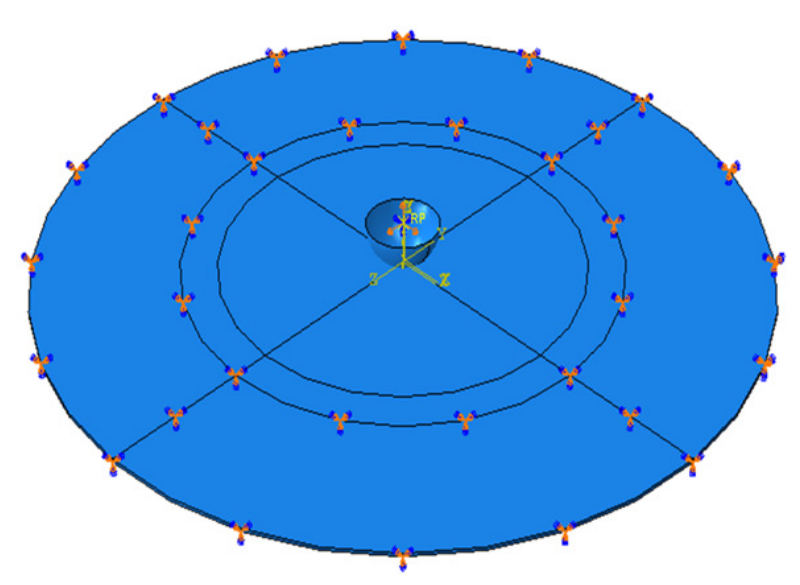

Fig. 10. The part and the punch and their interactions in FEM simulation.

\subsection{Conclusion}

The efforts of forming in a single point incremental sheet forming SPIF can be reduced and presented by their $F z$ component. An increase of one of the factors of this process such as the thickness of sheet $(e)$, the angle of inclination $(\alpha)$, the increment $(\Delta z)$ and breaking strength results in an increase in the $F z$ force, confirmed by the results found by Filice [4], Ambrogio [9].

\section{Finite element simulation}

To see the evolution of the efforts in a single point incremental sheet forming SPIF and to compare them with experimental work, a finite element simulation of the process is made on the Abaqus code, with the same experimental working conditions. For modelling and simulation in finite elements the law of behaviour selected is the elastoplasticity with isotropic work hardening [10,11], whose model is obtained following uniaxial tensile tests.

The blank is modelled by a deformable solid of circular form with $2 \mathrm{~mm}$ of thickness; a distribution is carried out to define several zones of which a crown dedicated to the fixed zone. The punch is modelled by a rigid solid with hemispherical form (Fig. 10). Amplitudes according to three directions are defined, for displacement of the punch in order to create the course already used during the experimental tests $[3,8,12,13]$ (Fig. 11).

The efforts behaviour results of the finite element simulation of a single point incremental sheet forming SPIF for the stainless $304 \mathrm{~L}$ blank with characteristics $\left(e=2 \mathrm{~mm}, \Delta z=1 \mathrm{~mm}\right.$ and $\left.\alpha=45^{\circ}\right)$ are given by Figure 12.

$F x$ and $F y$ forces evolve in an exponential envelope of share and others with a $(\pi / 2)$ dephasing and reach a maximum lower than for $F z$ (Fig. 13) [12].

The efforts resulted from the experiment approach those of finite element simulation; the results are aligned with those published by Jesweit [3], Doufflou [5] and Fratini [14]. 

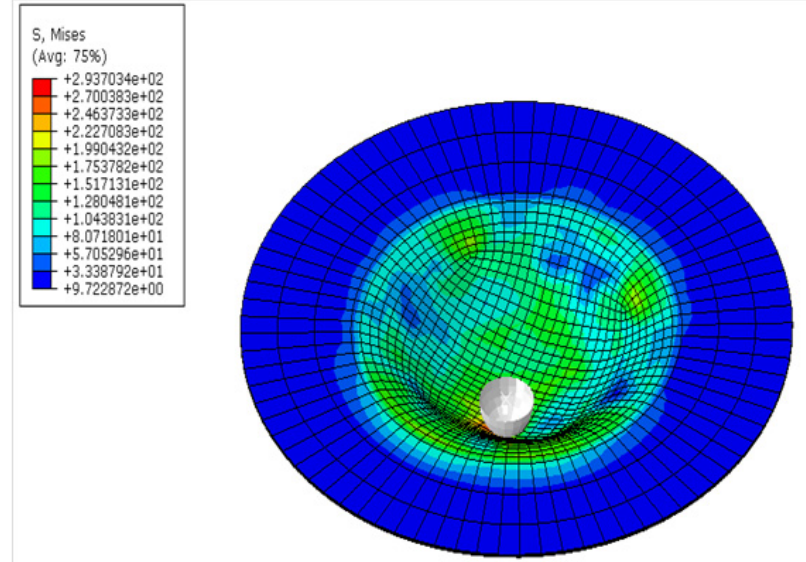

Fig. 11. Results of FEM simulation of single point incremental sheet forming.

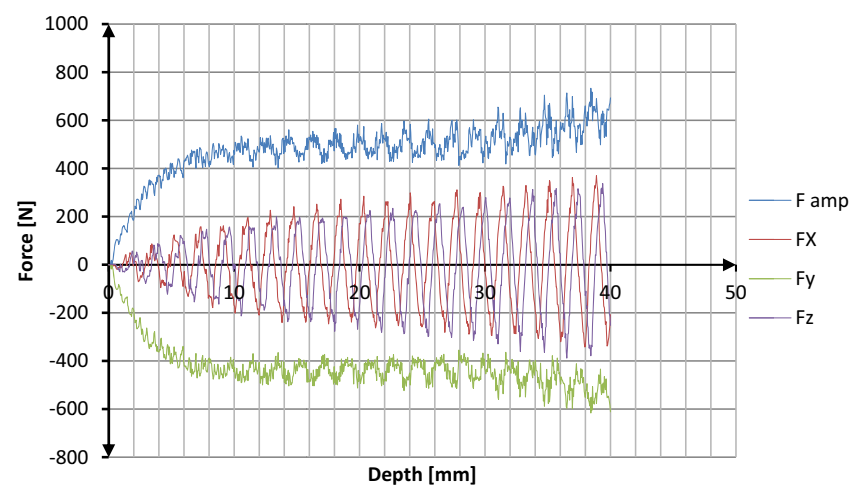

Fig. 12. Evolution of the efforts of FEM simulation.

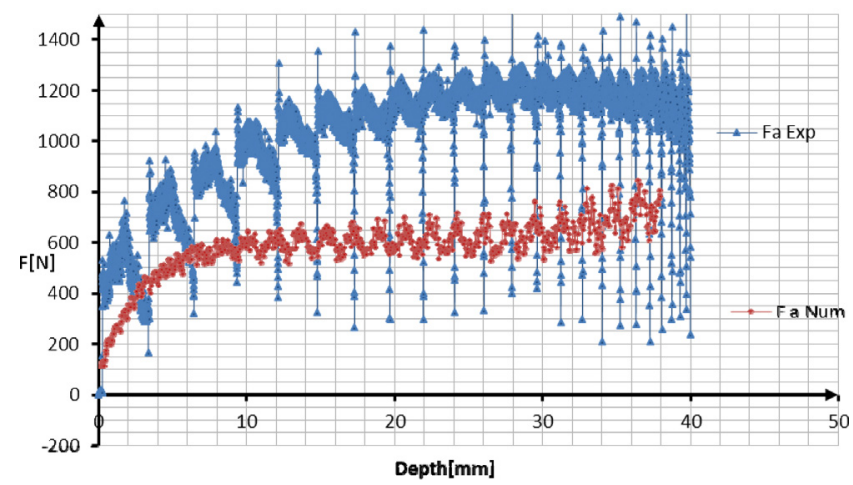

Fig. 13. Comparison of experimental and numerical amplitudes efforts in case of parameters (steel $304 \mathrm{~L}, e=2 \mathrm{~mm}$, $\Delta z=1 \mathrm{~mm}$ and $\alpha=45^{\circ}$ ).

\section{Conclusion}

The partner of the experimental tests carried out on two different materials, the steel $304 \mathrm{~L}$ and the aluminium alloy AA1050-0, with different mechanical characteristics, allowed us to extract a revealing set of results from the single point incremental sheet forming SPIF process.
- The behaviour of material in particular, by the evolution of the efforts necessary to forming confirm the results illustrated by the other authors.

- An increase of one of the factors of this process such as the thickness of sheet $(e)$, the angle of inclination $(\alpha)$, the increment $(\Delta z)$ and breaking strength of material results in an increase in the $F z$ force.

- Experimental efforts and FEM simulation results are similar in their aspects with a difference in values, and confirmed the results of Jesweit [3], Doufflou [5] and Fratini [14].

- Values found for efforts by numerical simulation are much lower than those found experimentally as well as the work of other authors because we ignored the steel damage to the model chosen for the material.

\section{References}

[1] E. Leszek, Apparatus and process for incremental dieless forming, 1967

[2] B. Saidi, Prédictions des efforts de formage incrémental à un point SPIF, École supérieure des sciences et technique de Tunis, Tunis, 2013

[3] J. Jeswiet, Metal forming progress since 2000, CIRP J. Manuf. Sci. Technol. 12008 (2008) 2-17

[4] L. Filice, On-Line Control of Single Point Incremental Forming Operations through Punch Force Monitoring, 2006

[5] J. Duflou, Experimental study on force measurements for single point incremental forming, J. Mater. Process. Technol. 1189 (2007) 65-72

[6] J.R. Duflou, Twist revisited: Twist phenomena in single point incremental forming, CIRP Ann. Manuf. Technol. 159 (2010) 307-310

[7] J.J. Park, Incremental forming of free surface with magnesium alloy AZ31 sheet at warm temperatures, Trans. Nonferrous Metal Soc. China 118 (2008) 165-169

[8] M. Durante, Comparison between analytical and experimental roughness values of components created by incremental forming, J. Mater. Process. Technol. 1210 (2010) 1934-1941

[9] G. Ambrogio, Influence of some relevant process parameters on the dimensional accuracy in incremental forming: a numerical and experimental investigation, J. Mater. Process. Technol. 1153-154 (2004) 501-507

[10] C. Robert, Contribution a la simulation numérique des procédés de mise en forme, application au formage incremental et au formage superplastique, École doctorale No. 432: Sciences des Métiers de l'Ingénieur, France, 2009

[11] N. Decultot, Formage incrémental de tôle d'aluminium: étude du procédé à l'aide de la mesure de champs et identification de modèles de comportement, Université Paul Sabatier, Toulouse 3, France, 2009

[12] R. Aerens, Force prediction for single point incremental forming deduced from experimental and FEM observations Int. J. Adv. Manuf. Technol. (2009)

[13] Y. Kim, Effect of process parameters on formability in incremental forming of sheet metal, J. Mater. Process. Technol. 130-131 (2002) 42-46

[14] L. Fratini, Influence of mechanical properties of the sheet material on formability in single point incremental forming, 2002 